\title{
Música despersonalizada y música participativa: Una propuesta terminológica desde la sociomusicología
}

\author{
Depersonalized and participative music: A terminological \\ proposal from sociomusicology
}

\author{
Xavier Mas i Sempere \\ Universitat de València, \\ mas.sempere@gmail.com (ESPAÑA)
}

Recibido: 07.072016

Aceptado: 06.09.2017

\section{RESUMEN}

La música, a pesar del ingente trabajo realizado desde la Filosofía, la Sociología y la Musicología, sigue utilizando cotidianamente un aparato conceptual poco riguroso. Todavía hoy se utilizan términos que proceden del ámbito linguístico coloquial, con una carga ideológica notable y basados en una visión de la realidad social sesgada de forma etnocéntrica y elitista. Otro elemento que se suma a esta rémora científica es el pecado original que supone la división entre Musicología - centrada en la historia y ciencias de la música que se producía en las academias occidentales- y la Etnomusicología -ocupada en las manifestaciones del resto de las otras sociedades y de los otros grupos sociales, rurales, fundamentalmente. Esta consideración paternalista y discriminadora tiene que superarse con reflexiones holísticas que se aparten de los apriorismos ideológicos y que puedan identificar las características de las diferentes sociedades aunando la capacidad crítica y multidisciplinaria de la Sociomusicología.

Para analizar la realidad musical de las sociedades capitalistas, nuestra propuesta toma como base el poder. Recuperamos, así, la propuesta teórica de Jesús Ibáñez en la que se identifica a las élites como las únicas capaces de extraer información de otros estratos sociales y, a la vez, inyectar neguentropía para conservar el statu quo. Y su teorización sobre la termodinámica de los procesos de producción, circulación y consumo del capitalismo. Planteamos, así, una doble división estructurada según la producción y/o la reproducción quede en manos de las élites o se comparta con las clases subordinadas. Proponemos para ello una nueva terminología alejada de planteamientos acríticos y basada en las lógi- 
cas de las propias manifestaciones artísticas. En definitiva, una propuesta teórica adecuada al rigor científico y que pretende desmontar el gran mito de la música: cómo el planteamiento esotérico y mágico de la música escondía el dominio de los medios de producción artística por parte de las elites.

\title{
PALABRAS CLAVE
}

Sociomusicología, teorización, terminología, capitalismo, música despersonalizada, música participativa.

\begin{abstract}
Music, despite the huge progress made in Philosophy, Sociology and $\mathrm{Mu}-$ sicology, still has a very large lax terminological framework. At present, terms from the informal register of language are used in scientific research even if they are ideologically charged and based on an elitist, ethnocentric and biased view of the social reality. Furthermore, the division between Musicology -focused on the study of history and science of Western Art music- and Ethnomusicology -which makes its research on other societies and other social groups, especially, rural ones- represents a hindrance for scientific activity. These paternalistic and discriminatory values must be overcome with holistic approaches. We need to surpass the ideological apriorism and combine the multidisciplinary and critical point of views in order to identify the characteristics of each society.

In order to analyze the capitalist societies' musical environment, we focus our proposal onto the concept of power. So, we rescue the theoretical paradigm from Jesús Ibáñez who identifies the elites as the only group capable of extracting information from other social classes while, simultaneously, injecting negentropy in order to preserve the status quo. Furthermore, we include his theoretical work on thermodynamic processes of capitalism production, circulation and consumption. We suggest, thus, a double division based on whether the production and/or the reproduction is reserved for upper classes or shared with subordinate classes. Our work proposes a new terminology based on the logics from the artistic events and away from acritical approaches. In conclusion, this is a theoretical proposal which matches the scientific rigor with which we intend to reveal the great musical myth: how the upper classes used to hide their domain of the productive resources with a magical and esoteric discourse.
\end{abstract}

\section{KEY WORDS}

Sociomusicology, theorization, terminology, capitalism, depersonalized music, participative music. 


\section{INTRODUCCIÓN:}

La música, a pesar del ingente trabajo realizado desde la Filosofía, la Sociología y la Musicología, sigue utilizando cotidianamente un aparato conceptual poco riguroso. Todavía hoy se utilizan términos que proceden del ámbito lingüístico coloquial, con una carga ideológica notable y basados en una visión de la realidad sesgada de forma etnocéntrica y elitista. Otro elemento que se suma a esta rémora científica es el pecado original que supone la división entre $\mathrm{Mu}$ sicología -centrada en la historia y ciencias de la música que se producía en las academias occidentales- y la Etnomusicología -ocupada en las manifestaciones del resto de las otras sociedades y de los otros grupos sociales, rurales, fundamentalmente. Esta consideración paternalista y discriminadora tiene que superarse con reflexiones holísticas que se aparten de los apriorismos ideológicos y que puedan identificar las características de las diferentes sociedades aunando la capacidad crítica y multidisciplinaria de la Sociomusicología.

Para analizar la realidad musical de las sociedades capitalistas, nuestra propuesta toma como base el poder. El binomio que estructura la dualidad entre los que tiene acceso al poder -entendido como acumulación de riqueza- y los que no marca el eje principal de nuestra división. Recuperamos, así, la propuesta teórica de Jesús Ibáñez (1997: 66) en la que se identifica a las élites como las únicas capaces de extraer información de otros estratos sociales y, a la vez, inyectar neguentropía para conservar el statu quo. También, utilizamos la teorización sobre la termodinámica de los procesos de producción, circulación y consumo del capitalismo (Ibáñez, 1986). Así pues, vinculamos ambas ideas a las diferentes partes del proceso de producción y reproducción que, tanto en la lógica de mercado y simbólica como en la música, tiene lugar. Finalmente, y para completar nuestra propuesta, tomamos elementos de la estructura de la comunicación.

El objetivo principal de este trabajo es proponer una nueva división de la música occidental y un nuevo aparato conceptual riguroso y ajustado a las exigencias científicas. Para ello partimos de nuestro ámbito de conocimiento más cercano y del que más abundantemente se ha ocupado la Musicología: la música clásica. A partir de una recopilación terminológica inicial, pretendemos demostrar nuestra hipótesis de partida: la terminología actual contiene un enorme sesgo $\mathrm{y}$, por ello, el sujeto investigador se ve obligado a utilizar construcciones léxicas y eufemismos que van en detrimento de la claridad y la precisión que se le exige al trabajo científico.

Así pues, el presente trabajo se sustenta, metodológicamente, en una extensa revisión bibliográfica construida a partir de la búsqueda online de materiales científicos con las diferentes variantes -en español e inglés- de la terminología habitual de la música clásica. El trabajo posterior de propuesta teórica se construye sobre una traslación de las aportaciones de Jesús Ibáñez al ámbito de la música. 


\section{2. ¿UNA CUESTIÓN DE NOMBRES?}

El término música clásica forma parte de la vida cotidiana. Precisamente, por su notable relevancia social (Martí 1995), está incluido en la cosmovisión contemporánea. No habría de resultar extraño, por tanto, que, interrogado por este concepto, un interlocutor cualquiera nos respondiese tarareando el acéfalo inicio de la Sinfonía $n^{o} 5$ de Beethoven, silbando el Allegro inicial de la Eine kleine Nachtmusik de Mozart, o que nos sorprendiese con el motivo que ideó Vivaldi para abrir su Concierto $n^{o} 1$ en Mi mayor, Op. 8 -y que se conoce, popularmente, como "la Primavera".

Este concepto, perfectamente válido en las interacciones familiares y coloquiales, presenta no pocos problemas cuando se utiliza en el ámbito científico. La mayoría de las veces, se utiliza por inercia: por un seguir la tradición sin dar lugar a la reflexión previa y porque, dada su difusión a todos los ámbitos sociales, serviría, hipotéticamente, para posibilitar un entendimiento más inmediato.

El mercado utiliza esta etiqueta con el fin de organizar sus escaparates y localizar fácilmente a su potencial clientela. Las discográficas la usan con normalidad en sus eslóganes: "Deutsche Grammophon ist klassische Musik" [Deutsche Grammophon], "Home of the legendary, London-based classical music label and home to the stars of classical music" [Decca Classics]. Y la incluyen, aún más, en los nombres de los propios sellos, por ejemplo, la ya mencionada Decca Classics, Warner Classics o las desaparecidas Emi Classics y Virgin Classics.

Científicamente, es un término conflictivo. Plantea, un equívoco con la música del período Neoclásico (el Clasicismo de Mozart, Haydn y el primer Beethoven). Por ello, y sobre todo desde el ámbito musicológico, se ha optado en ocasiones por una terminología alternativa: música culta (o art music en el ámbito anglosajón [Born \& Hesmondhalgh 2000: 2]). Ambas propuestas incorporan una lógica social de discursos impregnados de elitismo cultural y de sesgo etnocéntrico. En otras ocasiones, se intenta justificar la idea de clásica asociándola a otras acepciones del término clásico -más cercanas a las de la literatura-: "Que se tiene por modelo digno de imitación en cualquier arte o ciencia" (Acepción 3 del Diccionario de la RAE). En esta ocasión, y por otro lado, implica obviar a la música que, dentro de esta tradición, se está componiendo actualmente y que, inherentemente a la novedad, todavía no ha podido constituirse como modelo.

Esta situación, y la falta de propuestas de consenso, son los elementos que impulsan la elaboración del presente trabajo. Procederemos, pues, de la siguiente forma. En primer lugar, y considerando nuestro objetivo de delimitar y etiquetar, plantearemos el debate que existe acerca de las clasificaciones en la música y aportaremos algunos ejemplos de la complicación léxica que supone la falta de términos adecuados. En segundo lugar, expondremos algunas concepciones del arte musical y repasaremos la terminología actual. Finalmente, y como paso necesario a una revisión de las clasificaciones históricas -que habremos de plantear en otro momento-, presentaremos nuestro aparato conceptual y justificaremos su adecuación para el ámbito científico y artístico.

Nuestro planteamiento sociomusicológico nos permite aunar las conside- 
raciones teóricas y empíricas de ambas disciplinas. Así como, también, sumar las aportaciones efectuadas desde la filosofía y el pensamiento. Pretendemos, como requiere Vieira de Carvalho a la Musicología, "proceder à desconstrução do próprio paradigma [...] como consequência inevitável do reconhecimento do carácter ideológico desse paradigma" (1991: 13). Negando, aún más, el principio de autonomía estética del arte sonoro y procediendo a "estudar a música em sociedade (porque não existe fora desta!)" (1991: 16).

\section{SOBRE LAS CLASIFICACIONES, LAS ETIQUETAS Y LOS EUFEMISMOS}

"Must all such classifications-that is, must the recognition of difference in music - necessarily be fictive and divisive, ideological and hierarchical? Or can it be allied to a reflexive, analytical project?" (Born y Hesmondhalgh 2000: 2) La pregunta que plantean Georgina Born y David Hesmondhalgh es una buena muestra del debate que nos atañe y un excelente punto de partida para nuestra reflexión.

Existe, entre la comunidad artística actual, una cierta tendencia a eliminar las etiquetas: a criminalizar las divisiones -quizás, en pos de una homogénea y democrática consideración del arte.

"En un món eminentment global i globalitzat, les fronteres entre estils musicals i artístics esdevenen cada cop menys diàfanes, més difícils de distingir i fins i tot, tal vegada, pràcticament inexistents. Cada cop són més els artistes de formació clàssica que fan incursions en l'àmbit pop, com també creixen els artistes d'aquest segon grup que volen fer la seva particular lectura -sempre sense complexos- d'un clàssic" (Pérez Senz 2014: 38)

La corriente de la omnivoridad cultural, que defiende "la capacidad nueva de los actores para mezclar formas distintas de preferencias en un único menú" (Ariño Villarroya 2007: 133), se sumaría a esta tendencia de hibridación artística. Con un consumo poliédrico, supuestamente, perdería sentido la necesidad de establecer divisiones y clasificaciones.

En la misma línea se manifiesta el crítico musical de The New Yorker, Alex Ross. En su ópera prima, dedicada a la divulgación de la música de los siglos XX y XXI, concluye: "No hay manera de escapar a la interconexión de la experiencia musical, a pesar de que los compositores intenten atrincherarse frente al mundo exterior o controlar la recepción de su obra. [...] Un posible destino para la música del siglo XXI es una «gran fusión» final: los artistas pop inteligentes y los compositores extravertidos hablando más o menos el mismo idioma." (Ross 2009: 667-668). De hecho, en su siguiente trabajo se dedicó a establecer un diálogo entre lo que hasta ahora llamaríamos música clásica y la música popular y folklórica (Ross 2012).

En términos mucho más poéticos, se expresa Rodríguez Ferrándiz. "Las etiquetas culturales son muy tranquilizadoras, tanto como las que cuelgan, en las 
morgues, del dedo gordo del pie" (2010: 105). Según su consideración, la hibridación sería un fenómeno permanente de la cultura y no tendría sentido etiquetar como música clásica o música ligera.

A pesar de la línea trazada por estas reflexiones, consideramos que es imperioso -y una necesidad, como veremos, muy vigente e implícitamente demandada- establecer una conceptualización adecuada que dé sentido y articule coherentemente el ensamblaje estructural que nos presenta la realidad social. Tal y como resumía Carlos Vega

"Se trata nada más que de agrupar mentalmente productos musicales afines que oímos todos los días, valuar su presencia y su influjo, iluminar sus caminos, examinar su pasado, calcular su cifra atroz y darle un nombre al grupo. Se trata de distinguir y de nombrar lo distinto para entendernos mejor." (2007: 166).

Sabido es que nuestro pensamiento es posible gracias al lenguaje (Wittgenstein 2009) y, de la misma forma que "la información genética da forma al organismo, la información lingüística da forma al medio" (Ibáñez 1991: 25). La aprehensión de la realidad por medio de un cerebro humano se produce, por tanto, en sus mismos términos de funcionamiento. Nuestro pensamiento, según plantea la Gestalt se basa en la identificación de formas, en la discriminación de figuras concretas.

"Todas las clasificaciones hechas por el hombre son arbitrarias, artificiosas y falsas. Pero una consideración igualmente sencilla demuestra también que tales clasificaciones son útiles e indispensables y ante todo inevitables, porque corresponden a una tendencia innata de nuestro pensamiento" (Egon Friedell, citado en Berendt, 2000: 11)

Efectivamente, somos conscientes del principio de arbitrariedad que implica una clasificación. Aun así, la ciencia avanza por medio del cambio de paradigma científico y ese cambio no puede forzarnos a no tratar de dotarnos de herramientas para una mejor comprensión de la realidad. Afirmando el interrogante de Born y Hesmondhalgh, este proceso de clasificación y conceptualización ha de servir para reflexionar y analizar nuestra realidad actual. Nuestro planteamiento, desde el pensamiento crítico "es, a la vez, como la medida cuántica, transitivo (piensa el objeto) y reflexivo (piensa el pensamiento del sujeto sobre el objeto)" (Ibáñez 1991: 22).

En cualquier caso, siempre hablamos de una escucha ideológica. Según plantea Pérez Díaz, "[...] una cultura musical es básicamente una entidad cognitiva, definida por el conjunto de códigos y elementos retóricos que el oyente debe conocer para comprender correctamente lo que ha oído." (2005: 1417). Y dicha representación cognitiva estaría "entroncada con los aspectos de recepción de la música en la que en último término lleva a establecer el juicio al respecto, una recepción orientada en cierto modo en el sentido de la escucha del material implicado de forma más bien ideológica" (ibídem). Esta visión, coincide con la 
propuesta de Bourdieu, quien, en sus elementos de una teoría sociológica de la percepción artística afirma

"Toda percepción artística implica una operación consciente o inconsciente de desciframiento [...] la 'comprensión' inmediata y adecuada sólo es posible y efectiva en el caso particular en que la cifra cultural que posibilita el acto de desciframiento es dominada completa e inmediatamente por el observador (bajo la forma de competencia o de disposición cultiva) y se confunde con la cifra cultural que ha hecho posible la obra percibida" (Bourdieu dentro de Silbermann et al 1971: 45).

Como se ha dicho anteriormente, nuestro objetivo de plantear una terminología adecuada y científicamente sostenible no es un propósito baladí. Más allá del sentido apasionante que pueda plantear el reto, y de la necesaria mirada global y transversal al hecho socio-comunicativo de la música, existe una demanda implícita en el conjunto de la comunidad científica. Hecho que se manifiesta, por ejemplo, en los diferentes eufemismos y giros lingüísticos que ha de utilizar el científico para referirse a la música clásica.

El recurso más habitual en la literatura científica, para superar este escollo terminológico, es la expresión "la llamada música clásica" -so-called classical music, en los textos en lengua inglesa. Una rápida búsqueda, a partir de esta construcción léxica, nos devuelve un conjunto de ejemplos -de piruetas y paños calientes lingüísticos- que tienen como única finalidad evitar decir lo que no se puede decir.

Pareyon (2010: 1) y Goehr (1992: 13), igual que Vila d'Abadal (2005: 99), utilizan la susodicha construcción: los primeros, "the so called classical music", el último, "la llamada música clásica”. Zubiaur (2005: 293), más inseguro todavía, añade una cauta cursiva: "la llamada música clásica". Ferro Bayona (2009: 81) opta, en cambio, por las comillas bajas: "la llamada «música clásica»"; mientras que Cho (2009: 87), prefiere unas comillas simples: "so-called 'classical' music". La mayoría de autores esquivan el incómodo problema con las comillas altas: Burge (2002: 31), Mitas (2009: 257), Núñez et al. (2002: 1055) y Salamone (2005: 741) se refieren a la "so-called "classical" music". En algunos casos, se completa la definición con sazón geográfico. Así, de la Fuente (2007: 406) nos habla de la "Western so-called 'classical' music" y Stein (1990: 213) de la "so-called "classical" music of the West". El mismo recurso es utilizado por Jorgensen (2003: 7) aunque, en este caso, con la duda puesta en el término artístico "Western "art" music, so-called classical music".

Sanden (2003: 807), plantea dos opciones equivalentes: "so-called "classical" music, or music of the Western Art tradition". Los dos sinónimos para Rosen (2000: 385) son "art music [...] so-called classical music". En esta misma visión, Alroth (2008: 27) prefiere, tipográficamente, "art music, or so called classical music". Edwards (1989: 515-517), a su vez, se decanta por "the clashes between jazz and "art music" [...] (or so called classical music)".

La confusión derivada de esta rocambolesca imprecisión lleva a Blauert (2013: 9) y a Jafflin (2013: 263) a considerar que la llamada música clásica es, 
en realidad, la producida en el periodo artístico del Clasicismo. Según Jafflin: “a new principle of construction which emerges in music during this same historical period, so-called classical music, the period tied to the names of Haydn, Mozart, and Beethoven and based on the construction of the «sonata form»". Para Blauert: "When the so-called classical music originated, that is, at the end of the 18th century, music was played with acoustical instruments".

Parece lógico que, existiendo esta confusión en la propia Musicología, las referencias desde otras disciplinas sean igualmente imprecisas. Lo era en el caso de Núñez et al (2002) -quienes presentaban un estudio sobre los efectos de la música en el sistema inmunológico y el desarrollo del cáncer-, y lo es en el caso de Martindale (2007: 146) -que aporta un estudio de historia de la literatura- y que también se decanta por la ya mencionada "so-called classical music". Un ejemplo más, una patente estadounidense, aporta incluso una coletilla estética: "so-called good classical music" (Kosugi et al, 1982: 4).

Para concluir este apartado, incluimos una cita del crítico Roger Alier (2008: 10). "[...] ese lenguaje universal que es la música, mal llamada pero siempre calificada como tal, clásica". Sin entrar a valorar la romántica concepción de lenguaje universal, volvemos sobre nuestra primera idea. La ciencia se basa en la exactitud de los términos, en el lenguaje concreto y la prescindencia del equívoco. Así pues, no podemos mantener por más tiempo el paradigma de la tradición: la excusa del "siempre fue asî" y "todo el mundo se entiende". En primer lugar, por quedar demostrado que no es así: no sirve para entendernos sino para causar confusión y errores. Y, en segundo lugar, porque la tradición puede superarse gracias a la ciencia.

\section{UNA PROPUESTA DESDE LA SOCIOMUSICOLOGÍA}

Evidentemente, la finalidad de cualquier planteamiento teórico es conseguir el establecimiento paradigmático de sus postulados. En nuestra aportación, queremos explicitarlo, nos ceñimos a la realidad de las sociedades capitalistas -capitalismo financiero, informacional o de consumo en su forma actual- configuradas a partir de los principios de la división del trabajo y consiguiente división en clases sociales. No podemos ocultar, así mismo, nuestra posición como miembro de una de estas sociedades, con formación académica tradicional dentro de la universidad y el conservatorio, y con un posicionamiento ideológico crítico y deliberadamente subversivo.

En una sociedad jerárquica el poder siempre se reserva a las clases dominantes. Como si de una mera translación se tratara, la historia occidental se ha desplazado de las monarquías absolutistas a las democracias formales representativas. En ambos casos, el acceso al poder se restringe a unos pocos individuos, precisamente, los mayores acumuladores de riqueza -bien sea capital natural, bien industrial-empresarial-. La perpetuación en el poder y el propio ejercicio del poder, les proporciona el monopolio de la legitimación, incluso, en el ámbito del arte. 
La élite, la única que puede desarrollarse en la lógica del hacer, se reserva la capacidad de extraer información de la base de la pirámide y darle forma por medio de la inyección de neguentropía (Ibáñez 1997: 66). Así pues, monopoliza la capacidad de determinar quién tiene la capacidad de crear música e interpretarla -capital cultural institucionalizado en los conservatorios- y qué música se debe consumir para distinguirse como miembro de estas élites -capital cultural objetivado en grabaciones en las casas o en entradas para los conciertos y capital cultural incorporado, más fácilmente, por medio del efecto Arrow generalizado (Bordieu 1987). El propio Bourdieu indica en su trabajo sobre la distinción que son estas elites las que determinan, mediante sus prácticas culturales, qué manifestaciones recibirán la etiqueta del buen gusto y por medio de las cuales se articulará la lucha en el campo de poder (Bourdieu 1991). En posteriores trabajos será necesario someter estos postulados al análisis de las diferentes estructuras sociales que se han dado en cada etapa del capitalismo. Dicha operación nos permitirá, aún más, comprobar la validez histórica -o las adaptaciones necesarias- de la presente propuesta.

La división que aquí planteamos sobre la música es binaria. Viene determinada por el grado de incidencia que permiten-toleran las élites sobre el proceso de reproducción (interpretación) musical. Cuando la reproducción musical queda restringida a las élites, hablaremos de música despersonalizada. Cuando la reproducción musical se abre a las clases subordinadas, hablaremos de música participativa.

Así pues, por ejemplo, en un concierto de la New York Philharmonic Orchestra en el que se interpreta la Sinfonía $n^{o} 103$ de Joseph Haydn veremos que los intérpretes que están reproduciendo la partitura forman parte de las élites culturales -unes élites, ahora bien, que constituyen "una fracción (dominada) de la clase dominante" (Bourdieu 1990: 96) ya que no gestionan los medios de producción culturales- con una formación musical y artística -que supone un considerable desembolso, por cierto, alejándose con ello de las posibilidades económicas más modestas- dilatada en el tiempo. El público, por su parte, no participa más que con el silencio. En determinadas ocasiones, los precios de estos espectáculos provocan que, incluso, el consumo se restrinja a las propias élites. En aquellos casos en que puedan acceder miembros de otras clases sociales, se tendrán que adaptar al ritual preestablecido.

Alrededor de esta música despersonalizada se ha generado y mantenido un imaginario colectivo -muy propio del Romanticismo- que nos habla de trascendencia y para el que el cuerpo es una molestia y un estorbo. El silencio del receptor no precisa de ningún ruido y nuestra fisiología -empezando por el propio latido que nos mantiene con vida- es muy ruidosa. El ideal de esta música, por tanto, es el desvanecimiento del cuerpo, la negación del sujeto en tanto que objeto físico, la presencia del alma etérea y vaporosa. El término despersonalizada, en su acepción psicológica, ilustra de una forma muy gráfica esta realidad social. Nos remite, de hecho, a un "trastorno físico de autoconsciencia" cuya sintomatología clínica "comporta una alteración de los sentimientos de ser y de tener un cuerpo" (Doron \& Parot 2008: 167). 
El término persona, cuerpo central del concepto despersonalizada, nos pone en relación con dos elementos (Ibáñez 2014: 88). El primero, en tanto que sujeto del enunciado, nos remite al rol o valor de uso del ser humano. El segundo, y siguiendo su origen etimológico latín, nos remite al vocablo máscara. Esa máscara trágica del teatro clásico ahora designa el equipaje social y cultural de los seres humanos, de los seres del humus. Cuando se pone en marcha el mecanismo de la despersonalización, se produce un proceso de aniquilación doble. Por un lado, se exige el desvanecimiento del cuerpo físico: no está permitida la emisión de ningún sonido y el ideal imposible es el de una audiencia en completo silencio. Por otro lado, se efectúa la eliminación del propio sujeto -se desenmascara. La persona que ocupa el rol de oyente, convertido ahora en mero objeto pasivo de la recepción sonora, se ve desprendido de su revestimiento social -de su másca$r a-$ y con ello la persona se convierte en personne, y ya no es nadie. El sujeto enunciador -el intérprete- por medio del mensaje -de la música- anula al sujeto del enunciado.

Si consideramos, aún más, las corrientes que plantean la vinculación del término persona a la utilidad de amplificación sonora de estas máscaras -per sonare - todavía quedará más claro la necesidad de desenmascarar al sujeto. Un sujeto que, ya hemos visto, está ritualmente obligado a permanecer callado y desvalijado, incluso, de la lógica del decir. Igual que en las democracias representativas actuales donde se puede votar, pero no se puede decir nada.

En cambio, y trayendo a colación un ejemplo de la otra tipología musical, podemos fijarnos en un concierto de Bon Jovi. La élite sociocultural ha sido igual que en el caso de la sinfonía- la que ha producido, por ejemplo, Livin' on a Prayer. Pero en el momento de reproducirla en un concierto, la interpretación se abre al resto de las clases sociales allí presentes -meticulosamente, por cierto, separadas en niveles VIP, a pie de campo o gradas-. La formidable instalación de elementos amplificadores permite que la música emitida desde el escenario pueda escucharse por todas partes y resuene por todos los órganos del cuerpo del oyente. Así mismo, en diversas ocasiones, Bon Jovi dirige el micrófono hacia el público y este toma el protagonismo interpretando -a soli- algunos fragmentos de la canción.

El cuerpo, efectivamente, está muy presente en esta tipología de música. A diferencia de la otra, el ideal de la música participativa es un espacio grande donde la gente pueda permanecer de pie, en movimiento constante, y participando en el espectáculo con todo tipo de movimientos y sonidos. Aquí veríamos reflejada la distinción que realiza Don Idhe de body music vs head music (2007). La implicación de la audiencia, en este caso, es indispensable y forma parte de la propia configuración del espectáculo. Por eso, hemos considerado que el elemento más representativo y merecedor de calificar la tipología es el término participativa.

Hecha esta primera distinción, aportamos dos definiciones provisionales de las dos grandes tipologías musicales que planteamos. 
Música despersonalizada: música producida por la élite social, el valor central de la cual es la producción. Se centra en el mensaje, con el prestigio como dispositivo de valoración y que tiene, como situación ideal, la comunicación trascendental a un alma que se ha desprovisto del sujeto en tanto que objeto físico.

Música participativa: música reproducida por las clases subordinadas y que puede estar producida por la élite o por las propias clases subordinadas. En el primer caso, se centra en el consumo y tiene como dispositivo de valoración el dinero. En el segundo caso, se centra en la circulación y tiene el placer como dispositivo de valoración. En ambos casos conecta con un planteamiento más corporal de la música y donde el arte es un elemento más cercano a la experiencia social.

Esta primera división binaria, como ya hemos visto, nos deja un elemento pendiente de profundización dentro de la música participativa donde es necesario que diferenciemos dos subtipos. En este caso, centrando nuestra atención en la producción de la música. Una diferenciación que no sería necesaria, en cambio, en el caso de la música despersonalizada donde la producción, siempre, está en manos de las élites -bien sea sean estas la iglesia, las cortes reales o los grandes multimillonarios.

En el apartado anterior hemos mencionado que la música participativa permite la reproducción por parte de las clases subordinadas. La producción, aun así, puede llevarse a cabo por las élites o se puede dejar, también, en manos de las clases subordinadas. El ejemplo que poníamos en el punto anterior sería el propio de la música participativa producida por la élite (cerrada). Un ejemplo de música participativa producida por los subordinados (abierta) no tendríamos, por ejemplo, en una cantada de albaes valencianas. La dulzaina y el tabal construir construyen, primero, una breve introducción -en tiempo ternario- sobre una melodía que siempre se abre a las variaciones. Después, el cantaor pone en música, de una forma melismática y y virtuosística, el texto que va improvisando el versaor. Es en este contexto, además, alejado del control que ejerce la élite sobre los discursos, donde puede haber un espacio para la crítica social y para la sátira política.

Esta combinación de divisiones nos deja el siguiente esquema sobre las tipologías musicales. 
Tabla I - Tipologías musicales, producción y reproducción

\begin{tabular}{|l|l|l|l|}
\hline \multicolumn{2}{|l|}{ Tipología } & Reproducción & Producción \\
\hline \multicolumn{2}{|l|}{ Música despersonalizada } & Élite & Élite \\
\hline Música participativa & cerrada & $\begin{array}{l}\text { Élite / Clases } \\
\text { subordinadas }\end{array}$ & Élite \\
\cline { 2 - 4 } & abierta & $\begin{array}{l}\text { Clases } \\
\text { subordinadas }\end{array}$ & $\begin{array}{l}\text { Clases } \\
\text { subordinadas }\end{array}$ \\
\hline
\end{tabular}

Esta triple división musical se puede asociar a los diferentes elementos que planteaba Jesús Ibáñez en su teorización sobre la termodinámica de los procesos de producción, circulación y consumo del capitalismo (1986).

En el caso de la música despersonalizada, encontramos su principal valor en la producción. Por eso hablamos de la producción de Ludwig van Beethoven, de las obras que escribió Leonard Bernstein o de las valiosas aportaciones de Schoenberg. En esta tipología musical todo gira alrededor de las obras -los opus- que tratan de estructurar y organizar en catálogos (Bach-Werke-Verzeichnis, Köchel Verzeichnis, Ryom-Verzeichnis). La historia y las ciencias que explican esta música lo hacen a partir de obras. Es, pues, el prestigio -como elemento vinculado a la lengua y el mensaje- el dispositivo de valoración principal.

En el caso de la música participativa cerrada es el consumo su valor principal. El objetivo que persiguen sus creadores es obtener el máximo nivel de consumo: ser líder en las listas de ventas, conseguir colocar la mayor cuantidad de unidades en el mercado (discos de oro, platino y diamante). Para eso, se invierten cantidades ingentes en elementos de márquetin y publicidad y en conseguir la mayor cantidad de repeticiones diarias en las emisoras de radio-fórmula. La música, en esta tipología, se objetiva en forma de moneda, de dinero. Y es el oro metálico su dispositivo de valoración principal.

Finalmente, cuando las clases subordinadas producen la música participativa, el valor central es la circulación. Se comparten sin contrapartida las ideas, se hace partícipe al grupo para que se sume al canto o para que añada variaciones. La música se enriquece con la transmisión horizontal -entre los diferentes miembros del grupo- y con la transmisión vertical -el aprendizaje que realizan las siguientes generaciones de los propios cantos del grupo-. Esta tipología musical está estrechamente vinculada al sujeto. Lo apela directamente, alude a su realidad más cercana e, inmerso en su producción y su reproducción, se hace partícipe -con todo el deseo del cuerpo y su sexualidad- del placer.

El esquema que resulta con las aportaciones de Jesús Ibáñez (1986) quedaría de la siguiente forma: 
Tabla II - Tipologías musicales, valor central y dispositivo de valoración

\begin{tabular}{|c|c|c|c|}
\hline \multicolumn{2}{|l|}{ Tipología } & Valor central & $\begin{array}{l}\text { Dispositivo de } \\
\text { valoración }\end{array}$ \\
\hline \multicolumn{2}{|c|}{ Música despersonalizada } & Producción & Prestigio (mensaje) \\
\hline \multirow[t]{2}{*}{ Música participativa } & cerrada & Consumo & Dinero (objeto) \\
\hline & abierta & Circulación & Placer (sujeto) \\
\hline
\end{tabular}

Todavía se puede dar un paso más, en nuestra teorización musical, con las aportaciones del propio Jesús Ibáñez: el principio que regula cada una de estas tipologías. El principio de mecanicidad (el dictado) es el que guía la música despersonalizada. De esta manera, cualquier propuesta artística que no sirva para mantener el statu quo y de distinción social, se ve desplazada y marginada de los circuitos y los mercados habituales. Es el caso, por ejemplo, de las músicas de vanguardia: en su proceso de reflexión sobre el arte terminan planteando preguntas incómodas para las élites. La respuesta del sistema a este desafío puede ser doble. Por un lado, puede expulsarla y negarle el prestigio. O, por otro lado, puede asimilar y establecer, para su consumo, un subsistema que todavía ahondará más en la exclusividad y la endogamia artística.

El principio de regularidad se encuentra en la música participativa cerrada. Aquí se pretende que el arte regule la vida cotidiana: que transmita mensajes acríticos y que sirva para reproducir y mantener el statu quo. Los flujos sociales acaban sendentarizados en unas prácticas que, a pesar de la aparente imagen de libertad, terminan sirviendo para fijar y profundizar las divisiones clasistas y para evitar la creatividad de las personas (mientras cantamos una música dada, no pensamos en crear otra). El sistema se expresa por boca de sus clases subordinadas. No hay peligro en unas clases que comunican, sólo, el mensaje que la élite quiere que transmitan: están desactivadas.

Finalmente, en el caso de la música participativa abierta se encuentra el principio de creatividad. Al contrario del orden procedente del orden, que predomina en la música despersonalizada, y el orden procedente del desorden en la música participativa cerrada, aquí encontramos orden procedente del ruido. El azar, articulado por medio de las mutaciones y las revoluciones, permite que las clases subordinadas puedan expresarse radicalmente libres. Que puedan cuestionar el sistema, que puedan relacionarse con él con potencia de pregunta: subversos -girando el sistema y observándolo por debajo- o reversos -mofándose de él (Ibáñez 1997: 64-65).

El esquema de las diferentes tipologías de música, según su principio regulador y la procedencia de su orden, quedaría de la siguiente forma: 
Tabla III - Tipologías musicales, principio regulador y origen del orden

\begin{tabular}{|l|l|l|l|}
\hline \multicolumn{2}{|l|}{ Tipología } & $\begin{array}{l}\text { Principio } \\
\text { regulador }\end{array}$ & $\begin{array}{l}\text { Orden originado a } \\
\text { partir de }\end{array}$ \\
\hline \multicolumn{2}{|l|}{ Música despersonalizada } & Mecanicidad & Orden \\
\hline Música participativa & cerrada & Regularidad & Desorden \\
\cline { 2 - 4 } & abierta & Creatividad & Ruido (azar) \\
\hline
\end{tabular}

La aplicación de esta propuesta conceptual nos permite, además de utilizar una terminología científicamente homologada, entender de una manera mucho más clara determinados elementos históricos. Por ejemplo, dos discursos que se difundieron, respectivamente, en la Edad Media y el Romanticismo y que vuelven a nosotros una y otra vez. En el primero, la iglesia católica nos dijo que la música era la mejor forma de hablar con Dios. En el segundo, por medio de sus respectivas élites, que la música es un lenguaje universal y una esfera inalcanzable e independiente del entendimiento humano. Algo que nos acaricia directamente el alma. La naturalización, como pasa en muchos otros elementos de la existencia, es la mejor forma que tienen las élites para escondernos algo: "la ideología burguesa disfraza la historia en naturaleza, la contingencia en necesidad: intenta fundar en razón natural el hecho histórico y contingente de su dominación" (Ibáñez 1991: 16). Ahora, nos cuesta librarnos de esa visión esotérica y mágica de la música. Nos hicieron creer que su mística era natural. Tras ello, ocultaban algo mucho más humano: su dominio y control de los medios de producción artísticos.

\section{CONCLUSIONES}

En el presente artículo, hemos demostrado la necesidad imperiosa de establecer una nueva clasificación y terminología para las diferentes músicas de las sociedades occidentales. A partir de un repaso al término música clásica, hemos comprobado como la falta de un aparato conceptual riguroso -en términos científicos- y consensuado nos empuja a la imprecisión léxica, al uso de eufemismos y, finalmente, a la reproducción de unos postulados ideológicos etnocéntricos y elitistas.

A fin de superar dichos obstáculos, hemos construido una propuesta que incluye elementos teóricos sociomusicológicos y que recupera para el ámbito musical las teorizaciones de Jesús Ibáñez sobre el poder y la termodinámica de los procesos del capitalismo. Nuestra aportación ahonda en la negación del principio de autonomía estética del arte y sitúa a la música deliberadamente en el centro de las tensiones sociales. A partir del concepto de élite del propio Ibáñez 
construimos, simultáneamente, una división binaria y ternaria de la música según se produzca, o no, una apertura de la producción y reproducción a las clases subordinadas.

La terminología propuesta, música despersonalizada y música participativa (abierta y cerrada), se ha elaborado a partir de un análisis de la situación comunicativa de cada una de las tipologías. Así, la primera nos remite a la quietud y la unidireccionalidad que se le impone al receptor. Circunstancias que encuentran, en la desaparición del escuchante, al oyente ideal. A este término, de origen psicológico, hemos contrapuesto el concepto de música participativa. En este caso, el producto sonoro demanda para su compleción la intervención sonora del público -en el caso de la tipología cerrada- o, directamente, su implicación protagonista -en el caso de la tipología abierta- configurando una estructura comunicativa descentrada y horizontal.

La aplicación de la propuesta de Ibáñez a la realidad musical nos he permitido avanzar en la profundidad del análisis. Hemos podido identificar, de esta forma, el valor central, el dispositivo de valoración, el principio regulador y el origen del orden de cada una de las tipologías musicales. Elementos, todos ellos, que dan coherencia a nuestra división y encajan -a modo de continuidad- con la situación musical y la realidad socioeconómica del capitalismo.

Este trabajo constituye un primer paso. Nuestra propuesta demanda, obviamente, una aplicación empírica a fin de confirmar su validez. Una puesta en práctica que tiene que acompañarse, además, del debate con los propios integrantes del campo del arte, con la confrontación a otras propuestas teóricas que han quedado fuera del espacio de este artículo y con ulteriores aportaciones sociomusicológicas. Además, y estamos ya trabajando en esta línea, es necesario llevar a cabo una relectura histórica de la música a partir de los conceptos aquí planteados y profundizar en los procesos que, a modo de sutura permeable, permiten la movilidad de las diferentes músicas entre la despersonalización y la participación.

\section{BIBLIOGRAFÍA}

AHLROTH, J. (2008): "Leave the cat in the box: Some remarks on the possibilities of role-playing game criticism", en Playground Worlds: Creating and Evaluating Experiences of Role-Playing Games, Helsinki, Ropecon ry, pp. 26-32.

ALIER, R. (2008): "Prólogo", en Guía universal de la música clásica, Barcelona Ediciones Robinbook, pp. 9-11.

ARIÑO VILLARROYA, A. (2007): "Música, democratización y omnivoridad”, Política y Sociedad, 44, pp. 131-150.

BERENDT, J. E. (2000): El jazz: de Nueva Orleans a los años 80, Madrid, Fondo de Cultura Económica.

BLAUERT, J. (2013): “Conceptual Aspects Regarding the Qualification of Spaces for Aural Performances", Acta Acustica United with Acustica, 99 (1), pp. 1-13.

BORN, G., \& HESMONDHALGH, D. (2000): Western Music and Its Others, London, University of California Press. 
BOURDIEU, P. (1987): “Los tres estados del capital cultural”, Sociológica, 5, pp. 11-17. BOURDIEU, P. 1990: “¿Cómo liberar a los intelectuales libres?”, en Sociología y Cultura, México, Grijalbo, pp. 107-117.

BOURDIEU, P. (1991): La distinción: criterio y bases sociales del gusto, Madrid, Taurus.

BURGE, D. (2002): "A Style to Fit the Purpose", Contemporary Music Review, 21 (1), pp. 23-33.

CHO, D. K. (2009): “Adorno on Education or, Can Critical Self-Reflection Prevent the Next Auschwitz?", Historical Materialism, 17 (1), pp. 74-97.

DE LA FUENTE, E. (2007). “The 'New Sociology of Art': Putting Art Back into Social Science Approaches to the Arts", Cultural Sociology, 1 (3), pp. 409-425.

DORON, R. \& PAROT, F. (2008): Diccionario Akal de la Psicología, Tres Cantos, Ediciones Akal.

EDWARDS, J. M. (1989): “Women and Music”, NWSA Journal, 1 (3), pp. 506-518.

FERRO BAYONA, J. (2009): La palabra en la música: ensayos sobre Nietzsche, Barranquilla, Ediciones Uninorte.

GOEHR, L. (1992): The Imaginary Museum of Musical Works: An Essay in the Philosophy of Music, New York, Oxford University Press.

IBÁÑEZ, J. (1986): “Termodinámica del regalo”, Revista de Occidente, 67, pp. 79-94.

IBÁÑEZ, J. (1991): El regreso del sujeto: la investigación social de segundo orden, Santiago de Chile, Editorial Amerinda.

IBÁÑEZ, J. (1997): A contracorriente, Madrid, Editorial Fundamentos.

IBÁÑEZ, J. (2014): Por una sociología de la vida cotidiana, Tres Cantos, Siglo XXI de España Editores.

IDHE, D. (2007): Listening and voice: Phenomenologies of sound, Albany, State University of New York Press.

JAFFLIN, K., COCHRANE, T., FANTINI, B., \& SCHERER, K. R. (2013): The emotional power of music: Multidisciplinary perspectives on musical arousal, expression, and social control, Oxford, Oxford University Press.

JORGENSEN, E. R. (2003): Transforming music education, Indiana University Press.

KOSUGI, Y., IKEBE, J., TAKAKURA, K., \& KUMAGAI, Y. (1982): Method and randomized electrical stimulation system for pain relief, disponible en https://www. google.tl/patents/US4338945 [consulta el 15 de agosto de 2017].

MARTI I PÉREZ, J. (1995): La idea de "relevancia social" aplicada al estudio del fenómeno musical, disponible en http://www.sibetrans.com/trans/articulo/301/la-ideade-relevancia-social-aplicada-al-estudio-del-fenomeno-musical\#nota23 [consulta el 23 de octubre de 2015].

MARTINDALE, C. (2007): "Deformation forms the course of literary history", Language and Literature, 16 (2), pp. 141-153.

MITAS, A. W. (2009): "Stimulation Methods in Music Therapy - Short Discussion Towards the Bio-Cybernetic Aspect", Journal of Medical Informatics \& Technologies, 13 , pp. 255-258.

NÚÑ̃Z, M. J., MAÑÁ, P., LIÑARES, D. et al. (2002): "Music, immunity and cancer", Life Sciences, 71 (9), pp. 1047-1057.

PAREYON, G. (2010): "Traditional patterns and textures as values for meaningful automatization in music", Musetti: Jäsentiedote / Suomen Etnomusikologinen Seura \& Suomen Musiikkitieteellinen Seura, 40 (2), pp. 53-59.

PÉREZ DÍAZ, P. (2005): "Una reflexión sobre el uso del concepto de música culta en la actualidad", Revista de Musicología, 28 (2), pp. 1413-1424. 
PÉREZ SENZ, J. (2014), “Músiques sense etiquetes”, Revista Musical Catalana, 341, pp. 38-45.

REAL ACADEMIA ESPAÑOLA (2001): Diccionario de la lengua española ( $23^{\mathrm{a}}$ ed.), disponible en http://dle.rae.es/ [consulta el 15 de agosto de 2017].

RODRÍGUEZ FERRÁNDIZ, R. (2010): "Música clásica y medios de comunicación: Roll over, Beethoven", Trípodos, 26, pp. 95-105.

ROSEN, C. (2000): Tradition without Convention: The Impossible Nineteenth-Century Project disponible en http://tannerlectures.utah.edu/ documents/a-to-z/r/Rosen 01. pdf [consulta el 15 de agosto de 2017].

ROSS, A. (2009): El ruido eterno, Barcelona, Seix Barral.

ROSS, A. (2012): Escucha esto, Barcelona, Seix Barral.

SALAMONE, F. A. (2005): "Jazz and its impact on European classical music", The Journal of Popular Culture, 38 (4), pp. 732-743.

SANDEN, P. (2003): "Glenn Gould and Recording Technology: Linking Popular and Classical Recording Practices", Practising Popular Music, pp. 807-815.

SILBERMANN, A., BOURDIEU, P., BROWN, R. L., CLAUSSE, R., KARBUSICKY, V., LUTHE, H. O., \& WATSON, B. (1971): Sociología del arte, Buenos Aires, Ediciones Nueva Visión.

STEIN, H. F. (1990): "The story behind the clinical story: An inquiry into biomedical narrative", Family Systems Medicine, 8 (2), pp. 213-227.

VEGA, C. (2007): "Mesomúsica: un ensayo sobre la música de todos", Estudios para los orígenes del tango argentino, Buenos Aires, EDUCA: Editorial de la Universidad Católica de Argentina, pp. 165-196.

VIEIRA DE CARVALHO, M. (1991): "Sociologia da música: elementos para uma retrospectiva e para uma definição das suas tarefas actuais", Penélope: Fazer E Desfazer a História, 6, pp. 11-19.

VILA D'ABADAL SERRA, L. (2005): “La dimensión humanística de la música en el ámbito escolar: ¿Enseñar o aprender música para qué?” en La dimensión humanística de la música: reflexiones y modelos didácticos, Madrid, Secretaría General Técnica - Subdirección General de Información y Publicaciones, pp. 95-116.

WITTGENSTEIN, L. (2009): Tractatus logico-philosophicus, Madrid, Editorial Gredos. ZUBIAUR, I. (2005): “Interpretación musical", Claves de Hermenéutica: para la filosofía, la cultura y la sociedad, Bilbao, Publicaciones de la Universidad de Deusto, pp. 293-296. 
